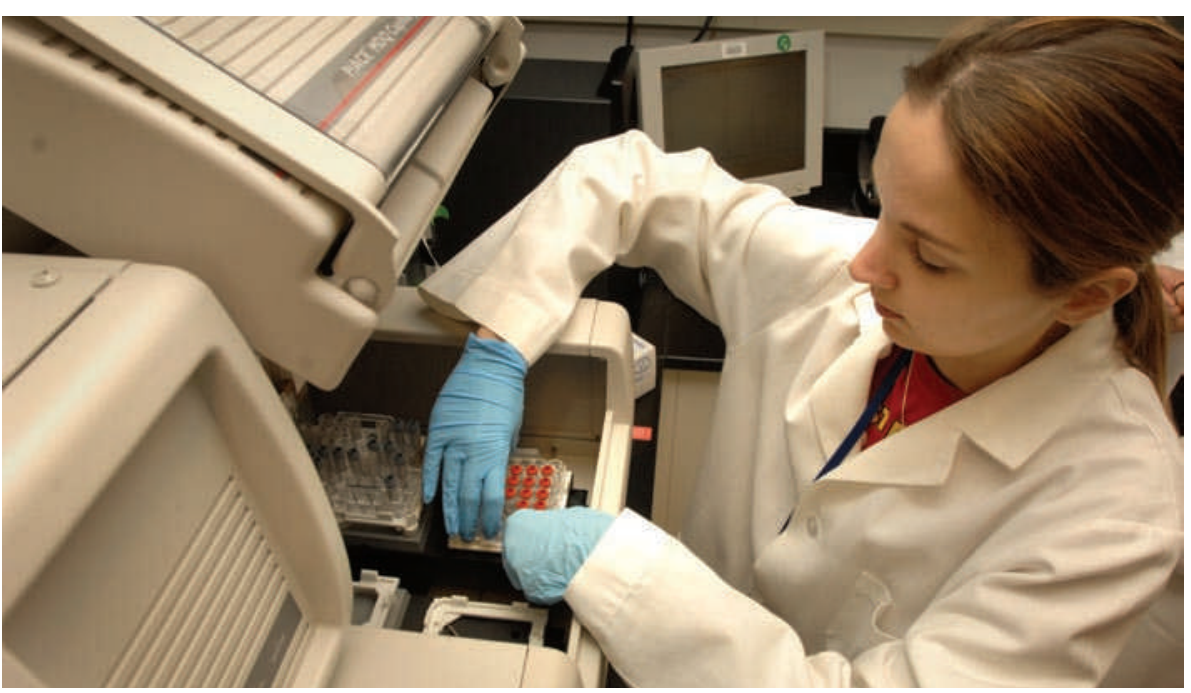

Some researchers contend that all addiction-related work should be overseen by one entity.

\title{
POLICY
}

\section{Plan for addiction institute splits NIH}

\section{Researchers are divided after a vote to combine work on drugs and alcohol in one unified body.}

\section{BY MEREDITH WADMAN}

$\mathrm{I}$ s alcohol a drug? Biochemically, the answer seems clear: the health effects of ethanol are well documented, as is its addictive nature. Yet culturally, politically and economically alcohol stands apart from other drugs, as does the research that has built up around it.

This conundrum has now acquired a practical urgency, thanks to a debate within the US National Institutes of Health (NIH). Should separate research institutes for drugs and alcohol be dissolved and replaced by a unified addictions institute?

"We've been talking about this for a dozen years. It's time to just do the right thing," said Harold Varmus, director of the National Cancer Institute and a proponent of the plan, at a meeting of the NIH's Scientific Management Review Board in Bethesda, Maryland, on 15 September. The board voted $12-3$ to recommend dismantling the National Institute on Drug Abuse (NIDA) and the National Institute on Alcohol Abuse and Alcoholism (NIAAA) in favour of a new entity that would house the addiction work of both, along with that of other $\mathrm{NIH}$ institutes. Non-addiction programmes would be moved elsewhere within the NIH.

Rarely has an issue caused such division in the NIH: earlier this year, advisers to NIAAA voted unanimously against the plan, whereas advisers to NIDA voted unanimously for it.

"It makes infinite scientific sense," says Alan Leshner, chief executive of the American Association for the Advancement of Science in Washington DC, who directed NIDA from 1994 to 2001. "There's no question that these are all drugs of abuse and addiction and they should be treated together, dealt with together."

"It's a terrible idea," counters Enoch Gordis, director of the alcohol institute for 15 years, until 2001. "This is not a meeting of equals. This is one institute trying to take over another."

\section{GRANT DATA DISTILLED}

Since 2004, alcohol-institute grant applicants have enjoyed discernibly better success rates than drug-institute grant applicants.

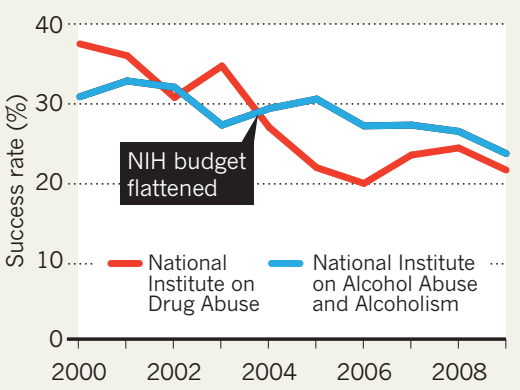

The angst at NIAAA stems in part from a fear of being swallowed: with a 2010 budget $\frac{\hat{z}}{z}$ of US\$462 million, the alcohol institute is less than half the size of the \$1-billion NIDA. Since 2004, external researchers funded by NIAAA have also enjoyed better grant-application success rates than have those seeking funding from the drug institute (see graph).

Alcohol-institute defenders argue that the loss of an independent NIAAA will discourage scientists from entering the field, obscure a social problem far more costly than drug abuse, rob the smaller institute of agility in responding to opportunities and imperil its systems approach to the study of alcohol toxicity. (Under the proposal, studies of end-organ damage such as liver cirrhosis, and of related conditions such as fetal alcohol syndrome, would move to other institutes.) Groups including the American Association for the Study of Liver Diseases in Alexandria, Virginia, and the National Organization on Fetal Alcohol Syndrome in Washington DC have vocally opposed the merger. So has Mothers Against Drunk Driving, a non-profit organization based in Irving, Texas.

Although the alcohol industry is unlikely to relish its legal product being lumped in for study with street drugs such as cocaine and heroin, it has so far remained silent. US Trade groups including the Beer Institute, the Wine Institute, the American Beverage Institute and the Distilled Spirits Council of the United States all declined to comment for this article.

Proponents of consolidation argue that because illegal-drug abusers and addicts often also abuse alcohol, their maladies are best understood and treated under the auspices of one institute. "The idea of a single strong institute that powerfully pushes forward the frontier in addiction research is certainly exciting," says Daniele Piomelli, a pharmacologist at the University of California, Irvine, who is funded by both institutes. Still, he adds, "the big risk is that in the end the overall funding will decrease, because we have one institute instead of two".

To move forward, the proposal must be approved by NIH director Francis Collins, be signed off by the Department of Health and Human Services and elicit no objections from Congress. Three weeks ago, Collins promised a decision "in the fairly near future" but didn't tip his hand. He is also considering an alternative proposal that would "functionally" integrate addiction research at the NIH through coordination and collaboration between institutes.

Smaller NIH institutes are eyeing the proceedings, wondering whether they will be next.

If there is an argument for consolidating institutes, "it is much more far-reaching than just merging two", says William Roper, a member of the NIH review board and dean of the University of North Carolina School of Medicine in Chapel Hill. Roper says that, if consolidation went ahead, he would choose to reduce the 20 current institutes to as few as 10, and "really have at it and make some significant changes". 